\title{
Inclusão de fontes de óleo na dieta de cabras em lactação: digestibilidade dos nutrientes e parâmetros ruminais e sangüíneos ${ }^{1}$
}

\author{
Fábio José Maia ${ }^{2}$, Antonio Ferriani Branco ${ }^{3}$, Gisele Fernanda Mouro ${ }^{4}$, Sabrina Marcantonio \\ Coneglian ${ }^{5}$, Geraldo Tadeu dos Santos ${ }^{3}$, Tathiane Fernanda Minella ${ }^{6}$, Francisco de Assis \\ Fonseca de Macedo ${ }^{3}$
}

\author{
${ }^{1}$ Parte da dissertação de Mestrado do primeiro autor. Financiamento CNPq. \\ 2 Mestre em Zootecnia pela UEM. Bolsista CAPES. \\ ${ }^{3}$ Departamento de Zootecnia da UEM - Av. Colombo, 5790 CEP: 87020-900, Maringá - PR. Pesquisador Bolsista do CNPq. \\ ${ }^{4}$ Doutora em Zootecnia pela UEM. \\ ${ }^{5}$ Doutoranda em Zootecnia da UEM \\ ${ }^{6}$ Graduação em Zootecnia da UEM - Bolsista de Iniciação Científica - CNPq
}

RESUMO - Os objetivos neste trabalho foram avaliar o efeito da inclusão de fontes de óleo na dieta de cabras em lactação sobre o consumo, a digestibilidade total dos nutrientes, a concentração de NDT e os parâmetros da fermentação ruminal. Foram utilizadas quatro cabras $(54 \pm 1,02 \mathrm{~kg}$ PV) Saanen canuladas no rúmen aos 80 dias em lactação. Os tratamentos consistiram de dietas suplementadas com diferentes fontes de óleo (canola, arroz e soja) e de uma dieta controle. Os dados foram analisados em um delineamento quadrado latino 4 x 4 utilizando-se o procedimento MIXED do SAS (2001), de modo que as diferenças entre as médias dos tratamentos foram determinadas por contrastes ortogonais, a 5\% de significância. A inclusão de óleos vegetais na dieta reduziu a digestibilidade da FDN e a digestão total dos CNF, mas não influenciou o conteúdo de NDT. A utilização de óleos vegetais também não provocou mudanças na concentração de N-NH3 ruminal (valor médio de 23,00 mg/dL), porém elevou o pH ruminal. Do mesmo modo, as fontes de óleo adicionadas às dietas não provocaram alterações na concentração de N-uréico no plasma (NUP), mas promoveram redução na concentração de $\mathrm{N}$ uréico no leite (NUL). A inclusão de $5,1 \%$ de óleos vegetais e de níveis de extrato etéreo superiores a 7\% na MS da dieta não altera a digestibilidade dos nutrientes e os parâmetros de fermentação ruminal de cabras em lactação.

Palavras-chave: óleo de arroz, óleo de canola, óleo de soja, pH ruminal

\section{Feeding vegetable oil to lactating goats: nutrient digestibility and ruminal and blood metabolism}

\begin{abstract}
The objectives of this trial were to evaluate the effect of dietary oil supplementation on intake, apparent total tract digestibility of nutrients, and ruminal metabolism in lactating Saanen goats. Four ruminally cannulated multiparous goats averaging $54 \pm 1.02 \mathrm{~kg} \mathrm{BW}$ and 80 days in milk were used. Goats were fed a control diet (no oil supplementation) or diets supplemented with one of the following oil sources: canola, rice or soybean. A 4 x 4 Latin square design was used and data were analyzed using the MIXED procedure of SAS (2001) with means compared through orthogonal contrasts at $5 \%$ of significance. Dietary oil supplementation reduced apparent total tract digestibility of both neutral detergent fiber and nonstructural carbohydrates but contents of TDN did not differ among diets. Oil supplementation did not change the concentration of ruminal ammonia $\mathrm{N}$ and plasma urea $\mathrm{N}$ but increased ruminal $\mathrm{pH}$ and decreased milk urea nitrogen concentration (MUN). The inclusion of $5.1 \%$ of vegetable oils in the diet of lactating goat did not significantly affect nutrient digestibility and ruminal fermentation parameters.
\end{abstract}

Key Words: rice oil, rapeseed oil, soybean oil, ruminal $\mathrm{pH}$

\section{Introdução}

Modificações nas características da dieta podem ser responsáveis por várias alterações no metabolismo ruminal, nos processos digestivos e, conseqüentemente, dos nutrientes que chegam ao duodeno. Apesar dessas alterações, a inclusão de fontes de óleo na dieta de ruminantes é uma alternativa para o atendimento às exigências de energia de animais de alta produção leiteira.

O uso de fontes de lipídios, tanto de origem animal quanto vegetal, em dietas para ruminantes ainda é motivo de muitas contradições, haja vista o conhecimento ainda restrito dos níveis e das formas de inclusão (protegidas ou não) e de seus efeitos no consumo. Fatores com ação 
potencial incluem a aceitabilidade das dietas, o efeito sobre as motilidades ruminal e intestinal, a liberação de hormônios intestinais e a oxidação das gorduras pelo fígado (NRC, 2001).

Estudos com inclusão de lipídios na dieta para avaliação do consumo e da digestibilidade dos nutrientes demonstram variações nos resultados, atribuídas à fonte lipídica utilizada, ao nível de inclusão ou à espécie animal. Romo et al. (2000) verificaram menor consumo de $\mathrm{MS}$ em vacas submetidas à infusão abomasal de misturas de isômeros cis- $\mathrm{C}_{18: 1} \mathrm{e}$ trans- $\mathrm{C}_{18: 1}$. Segundo Benson et al. (2001), os ácidos graxos poliinsaturados e não-esterificados parecem ser inibidores do consumo mais potentes que, respectivamente, os monoinsaturados e os esterificados. Estes dados indicam que a utilização de fontes lipídicas conhecidamente ricas em ácidos graxos poliinsaturados e não-esterificados podem influenciar o consumo de matéria seca.

Entretanto, Kelly et al. (1998) avaliaram fontes de óleos vegetais ricas em ácidos graxos poliinsaturados (oléico, linoléico e linolênico) na dieta de vacas leiteiras e verificaram que a ingestão de matéria seca não foi alterada pela fonte de lipídio adicionada à dieta.

Segundo Loor et al. (2002), a suplementação da dieta de vacas leiteiras com lipídios protegidos e óleo de canola não afetou a digestibilidade aparente da MS, PB e FDA no trato digestório total. Esses autores verificaram também $\mathrm{pH}$ ruminal mais elevado nas dietas com fontes de lipídio protegidas que com óleo de canola. Além disso, a concentração de nitrogênio amoniacal do rúmen diminuiu em resposta à suplementação lipídica, sendo menor para as fontes protegidas.

Estudos similares também indicaram diminuição da concentração de nitrogênio amoniacal quando uma dieta controle foi suplementada com óleo de linhaça (Igwuegbu \& Sutton, 1982) e óleo de canola (Ferlay et al., 1993).

Portanto, os parâmetros fermentativos do rúmen podem ser afetados pela adição de fontes de óleo à dieta. Porém, a extensão dessa interferência depende tanto da fonte de óleo como do nível em que é adicionada à ração. A maioria dos trabalhos confirma que o uso de lipídios exerce pouco ou nenhum efeito sobre as atividades da flora microbiana e as demais características do ambiente ruminal, desde que não ultrapasse o valor de 7\% da MS total da dieta.

Considerando os dados atuais sobre os efeitos da inclusão de fontes ricas de lipídeos em dietas para cabras em lactação, avaliaram-se os efeitos da inclusão de fontes de óleo, no nível de 5,1\% (com base na MS), na dieta total de cabras Saanen em lactação sobre o consumo, a digestibilidade total dos nutrientes, o pH, as concentrações de amônia ruminal e de $\mathrm{N}$-uréico no plasma e no leite.

\section{Material e Métodos}

O experimento foi realizado no período de outubro de 2002 a janeiro de 2003 na Fazenda Experimental de Iguatemi, distrito de Iguatemi, e as análises foram realizadas no Laboratório de Análises de Alimentos e Nutrição Animal do Departamento de Zootecnia da Universidade Estadual de Maringá.

Foram utilizadas quatro cabras lactantes Saanen com 80 dias em lactação, canuladas no rúmen, pesando $54 \pm 1,02 \mathrm{~kg}$ e com produção diária de $2,5 \pm 0,43 \mathrm{~kg}$ de leite. Os animais foram alojados individualmente em gaiolas de metal com piso de madeira ripada, providas de bebedouro e comedouro individuais.

A alimentação foi fornecida em duas porções iguais, às 8 e 16h, e a água foi disponibilizada ad libitum em bebedouros individuais. As gaiolas e as cânulas foram lavadas duas vezes ao dia para manutenção do controle higiênico/sanitário e as cabras foram ordenhadas duas vezes ao dia, às $8 \mathrm{~h} 30$ e $16 \mathrm{~h} 30$.

Os animais receberam dieta balanceada para atender às exigências de mantença e lactação, segundo o AFRC (1993), com relação volumoso:concentrado de 50:50. O volumoso foi composto de silagem de milho e o concentrado, de aveia, milho, farelo de soja, farelo de algodão, uréia, calcário e suplemento mineral. Os tratamentos avaliados consistiram da utilização de três fontes de óleo (canola, arroz e soja) na dieta, em nível de $5,1 \%$, e de um tratamento controle sem a inclusão de óleo, como descrito a seguir:

$\mathrm{TT}=$ sem adição de fonte de óleo na dieta;

TOA $=$ adição de $5,1 \%$ de óleo de arroz na dieta total; TOC $=$ adição de $5,1 \%$ de óleo de canola na dieta total; TOS $=$ adição de 5,1\% de óleo de soja na dieta total.

A composição dos alimentos empregados na formulação das dietas experimentais encontra-se na Tabela 1 e a das rações experimentais, na Tabela 2.

Foram estabelecidos períodos experimentais com 14 dias de duração. As amostras de alimentos e rações foram coletadas no momento da mistura e a cada 14 dias, de modo que as análises fossem realizadas para cada período. As sobras foram pesadas e amostradas diariamente e, posteriormente, foram misturadas para obtenção de uma amostra composta/animal/período.

As coletas de fezes foram realizadas do $9^{\circ}$ ao $13^{\circ}$ dias do período experimental. Foram amostrados aproximadamente $25 \mathrm{~g}$ de fezes a cada coleta, duas vezes ao dia, com início no 9 o dia às 8 e $13 \mathrm{~h}$, com incremento de uma hora a cada dia de coleta. Desse modo, foram realizadas dez amostragens/animal/período, incluindo amostras de fezes coletadas das 8 às $16 \mathrm{~h}$, ao longo do período de coleta. As 
Tabela 1 - Composição química dos alimentos utilizados nas dietas experimentais (\% na MS)

Table 1 - Chemical composition of feeds used in the formulation of the experimental diets (\% DM)

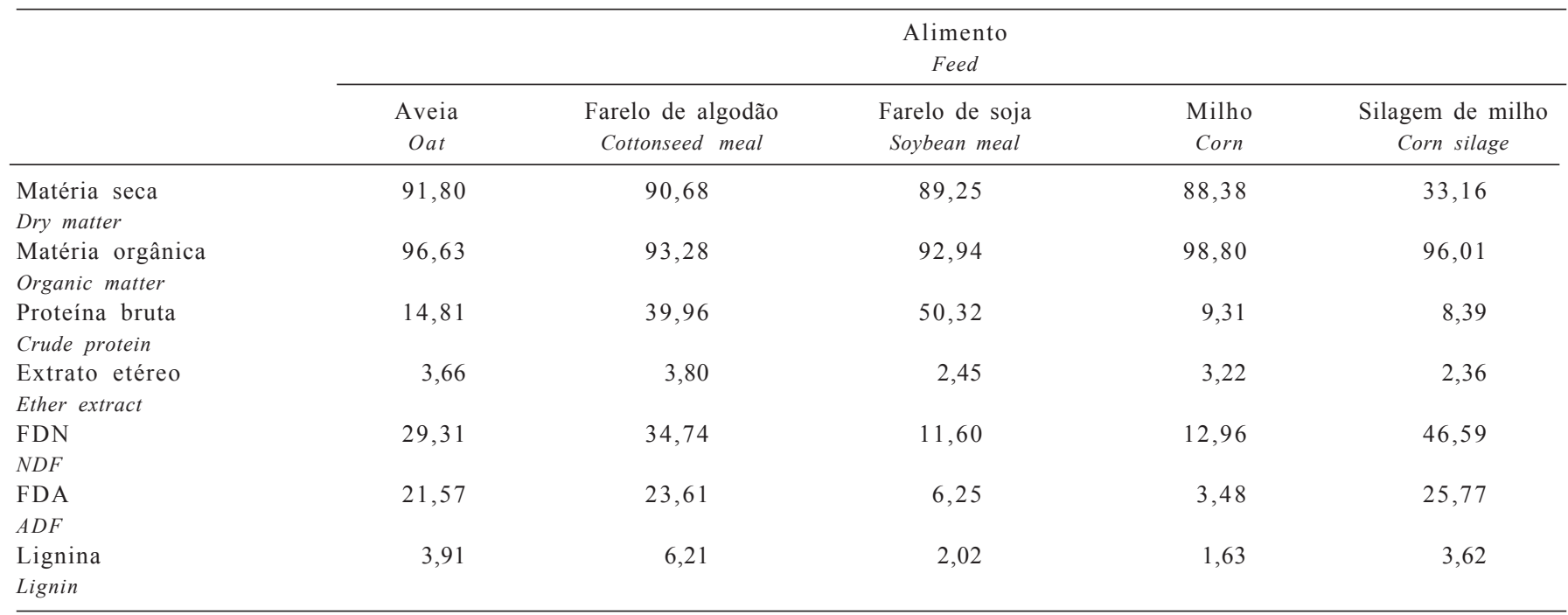

Tabela 2 - Composições percentual e química das dietas experimentais (\% na MS)

Table 2 - Ingredient and chemical compositions of the experimental diets (\% DM)

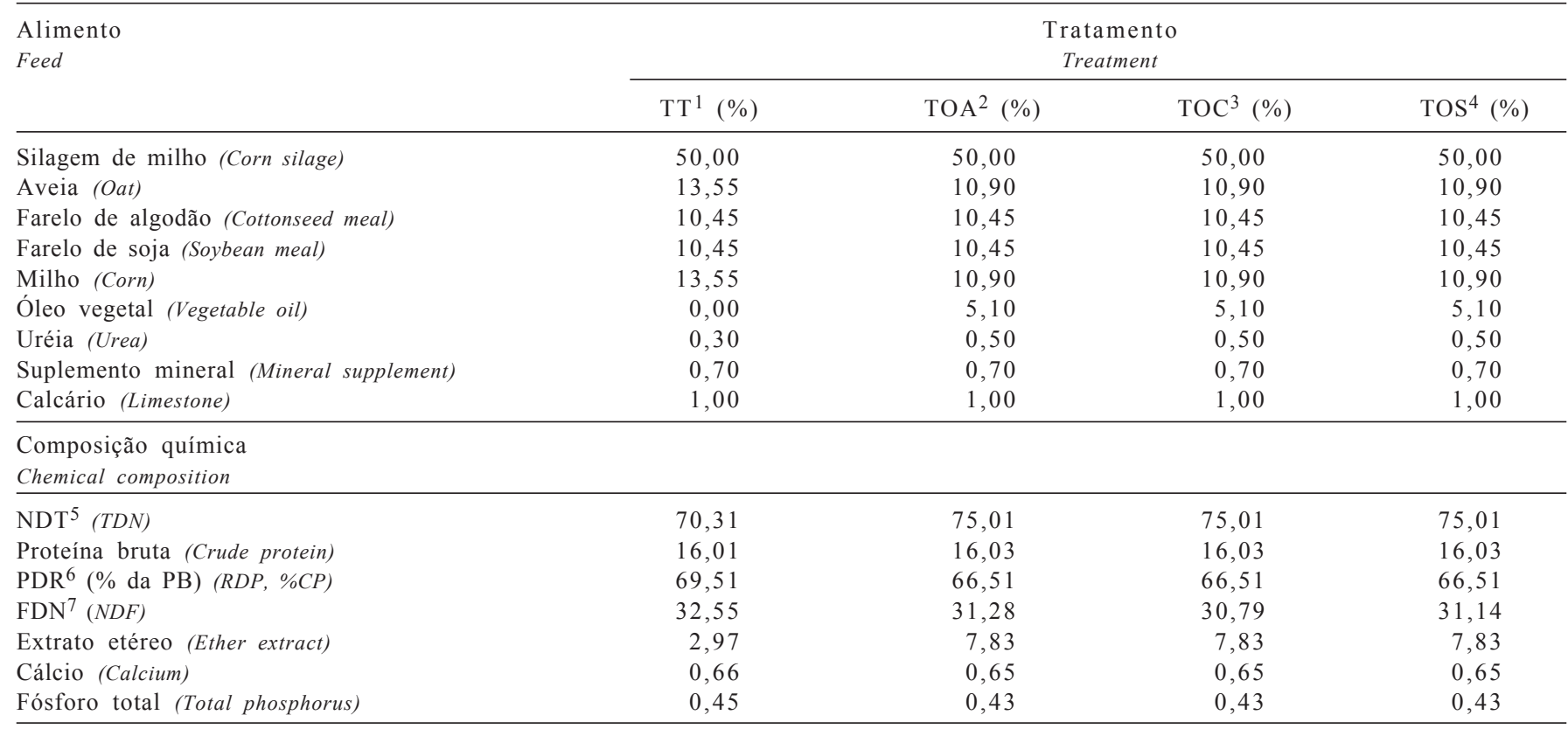

1 TT = Sem adição de óleo na dieta (control diet).

2 TOA = Adição de $5,1 \%$ de óleo de arroz na dieta (rice oil).

3 TOC $=$ Adição de $5,1 \%$ de óleo de canola na dieta (canola oil).

4 TOS = Adição de $5,1 \%$ de óleo de soja na dieta (soybean oil).

${ }^{5}$ Nutrientes digestíveis totais (Total digestible nutrients): estimado NRC (1996).

6 Proteína degradada no rúmen (Rumen-degradable protein): estimado NRC (1996).

${ }^{7}$ Fibra em detergente neutro (Neutral detergent fiber).

amostras foram misturadas àquelas coletadas nos horários anteriores, constituindo amostras compostas por tratamento/animal/período, que, posteriormente, foram secas em estufa de circulação forçada, a $55^{\circ} \mathrm{C}$ por 72 horas.

Os alimentos, as rações, as sobras e as fezes foram analisados quanto aos teores de MS, MO, PB e EE, de acordo com as metodologias descritas por Silva (1990). As determinações de FDN foram realizadas segundo Van Soest et al. (1991).

A fibra em detergente neutro indigestível (FDNi) foi utilizada como indicador interno para cálculo dos coeficientes de digestibilidade dos nutrientes analisados, sendo determinada a partir da metodologia descrita por Cochran et al. (1986). A partir da utilização do indicador, foram deter- 
minados os coeficientes de digestibilidade total de MS, $\mathrm{MO}, \mathrm{PB}, \mathrm{EE}$ e FDN.

A porcentagem de NDT foi determinada pela equação descrita por Sniffen et al. (1992):

$\mathrm{NDT}=\mathrm{PBD}+\mathrm{FDN}_{\mathrm{N}} \mathrm{D}+\mathrm{CNFD}+(\mathrm{EED} \times 2,25)$

em que: $\mathrm{NDT}=$ nutrientes digestíveis totais; $\mathrm{PBD}=$ proteína bruta digestível; $\mathrm{FDN}_{\mathrm{N}} \mathrm{D}=$ fibra em detergente neutro digestível corrigida para nitrogênio; $\mathrm{CNFD}=$ carboidratos não-fibrosos digestíveis; $\mathrm{EED}=$ extrato etéreo digestível.

sendo: $\mathrm{CNF}=100-\left(\% \mathrm{~PB}+\% \mathrm{FDN}_{\mathrm{N}} \mathrm{D}+\% \mathrm{EE}+\% \mathrm{MM}\right)$ em que: $\mathrm{CNF}=$ carboidratos não-fibrosos; $\mathrm{CIN}=$ cinzas .

As amostras de líquido ruminal para a determinação do nitrogênio amoniacal $\left(\mathrm{N}-\mathrm{NH}_{3}\right)$ e pH foram coletadas no $14^{\circ}$ dia do período experimental, das 8 às $20 \mathrm{~h}$, a cada 2 horas, procedendo-se imediatamente à determinação do $\mathrm{pH}$. Uma alíquota de $50 \mathrm{~mL}$ de líquido ruminal foi acidificada com $1 \mathrm{~mL}$ de ácido sulfúrico $20 \%$, dividida em dois recipientes de aproximadamente $25 \mathrm{~mL}$ cada e armazenada a $-20^{\circ} \mathrm{C}$, para posterior determinação dos teores de amônia, de acordo com técnica descrita por Vieira (1980).

As amostras de leite foram coletadas duas vezes ao dia (11을 $12^{\circ}$ e $13^{\circ}$ dias, às $8 \mathrm{~h} 30$ e $15 \mathrm{~h}$ ), sendo preservadas com 2-bromo-2-nitropropano-1,3diol (BRONOPOL) e refrigeradas a $4^{\circ} \mathrm{C}$. As amostras da manhã e tarde foram compostas para o 11으 $12^{\underline{0}}$ e $13^{\circ}$ dias. Posteriormente, foram centrifugadas $\left(3500 \mathrm{x}\right.$ g por 15 minutos a $\left.22^{\circ} \mathrm{C}\right)$ e mantidas no refrigerador por 24 horas, para retirada da camada sobrenadante, formada pela gordura. O leite desengordurado foi analisado quanto à concentração de uréia pelo método enzimático (urease/glutamato desidrogenase), segundo Talke \& Schubert (1965), utilizando-se o analisador automático Merch Vitalab Selectra ${ }^{\circledR} 2$.

As amostras de sangue foram coletadas diretamente da veia jugular de cada animal, duas vezes ao dia, às 10 e $18 \mathrm{~h}$, no $11^{\circ}, 12^{\circ}$ e $13^{\circ}$ dias de cada período experimental, e acondicionadas em tubos contendo heparina. Logo após as coletas, as amostras foram centrifugadas a $3500 \mathrm{x} g$ por 15 minutos. O plasma foi removido, congelado e posteriormente analisado para estimativa da concentração de uréia pela mesma metodologia aplicada ao leite desengordurado.

Os dados foram analisados em um quadrado latino 4 x 4 utilizando-se o procedimento MIXED do SAS (2001). As fontes de variação consideradas no modelo foram animal, período e tratamento. As diferenças entre as médias dos tratamentos foram determinadas por contrastes ortogonais, a $5 \%$ de significância. Os contrastes ortogonais avaliados foram controle x tratamentos (cont $x$ trat), óleo de arroz x óleo de sementes de oleaginosas (arr x ole) éleo de canola x óleo de soja (can x soj).

O modelo matemático utilizado na análise dos dados foi o seguinte:

$$
\mathrm{Y}_{\mathrm{ijk}}=\mu+\mathrm{T}_{\mathrm{i}}+\mathrm{A}_{\mathrm{j}}+\mathrm{P}_{\mathrm{k}}+\mathrm{e}_{\mathrm{ijk}}
$$

em que $Y_{i j k}=$ resposta observada; $\mu=$ constante geral; $\mathrm{T}_{\mathrm{i}}=$ efeito do tratamento $i$, variando de $1 \mathrm{a} 4 ; \mathrm{A}_{\mathrm{j}}=$ efeito do animal $j$, variando de 1 a $4 ; \mathrm{P}_{\mathrm{k}}=$ efeito do período $k$, variando de 1 a 4 ; e $\mathrm{e}_{\mathrm{ijk}}=$ erro aleatório associado a cada observação $i j k$.

\section{Resultados e Discussão}

A inclusão de óleo na dieta não influenciou $(\mathrm{P}>0,05)$ as ingestões de MS, MO, PB, FDN, CNF e NDT (Tabela 3). Não houve diferença $(\mathrm{P}>0,05)$ entre as fontes de óleo utilizadas na suplementação. As fontes de óleos vegetais incluídas na dieta também não influenciaram $(\mathrm{P}>0,05)$ a excreção fecal (EF), em g/dia, a digestão total (DT), em g/dia, e a digestibilidade total (DIG), em \%, da MS, MO e PB.

A ingestão de MS foi de 2,02 $\pm 0,06 \mathrm{~kg} \mathrm{MS} / \mathrm{animal} / \mathrm{dia}, \mathrm{o}$ que representa consumo de $3,73 \%$ do $\mathrm{PV}$, pois o fornecimento de MS foi limitado a 5\% do PV.

O consumo de dietas com altos níveis de EE pode comprometer a ingestão de alimentos por reduzir a digestão da fibra e a taxa de passagem da digesta pelo trato gastrintestinal, como resultado do efeito negativo da presença de gordura no ambiente ruminal sobre o crescimento microbiano, sobretudo dos microrganismos celulolíticos (NRC, 2001).

A redução das perdas gasosas também têm sido utilizada para explicar o efeito negativo sobre o consumo de MS pelos inibidores microbianos, como os lipídios e ionóforos (Goodrich et al., 1984). Segundo Chalupa et al. (1984), lipídios insaturados inibem as bactérias ruminais grampositivas e estimulam aquelas produtoras de propionato, normalmente atribuído à ação de ionóforos.

Outros estudos mostram ainda que a redução no consumo de MS, comumente verificada em trabalhos com fontes suplementares de lipídios na dieta, pode estar relacionada à concentração plasmática de determinados ácidos graxos resultantes do metabolismo dessas fontes lipídicas. Os principais ácidos graxos que parecem estar envolvidos neste mecanismo são o 18:2n-6 e o 18:1n-9.

Jenkins et al. (1996) não observaram redução na ingestão de MS em vacas alimentadas com 3,5\% de fontes de óleo protegidas, mesmo quando os animais apresentaram altas concentrações plasmáticas de 18:2n-6. Jenkins \& Thies (1997), em estudo realizado com ovinos alimentados com dietas ricas em ácidos graxos insaturados, verificaram redução no consumo de MS, como conseqüência da maior concentração plasmática de 18:2n-6. Vargas et al. (2002) encontraram efeito negativo dos lipídios sobre o consumo de MS, sem afetar os parâmetros ruminais, à exceção do pH, que foi aumentado com a inclusão de grãos de soja na dieta. 
Tabela 3 - Médias e coeficientes de variação (CV\%) para ingestão (ING), excreção fecal (EF), digestão total (DT) e digestibilidade total (DIG) dos nutrientes

Table 3 - Means and coefficients of variation for intake (INT), fecal excretion (FE), total digestion (TD), total digestibility (DIG) of nutrients

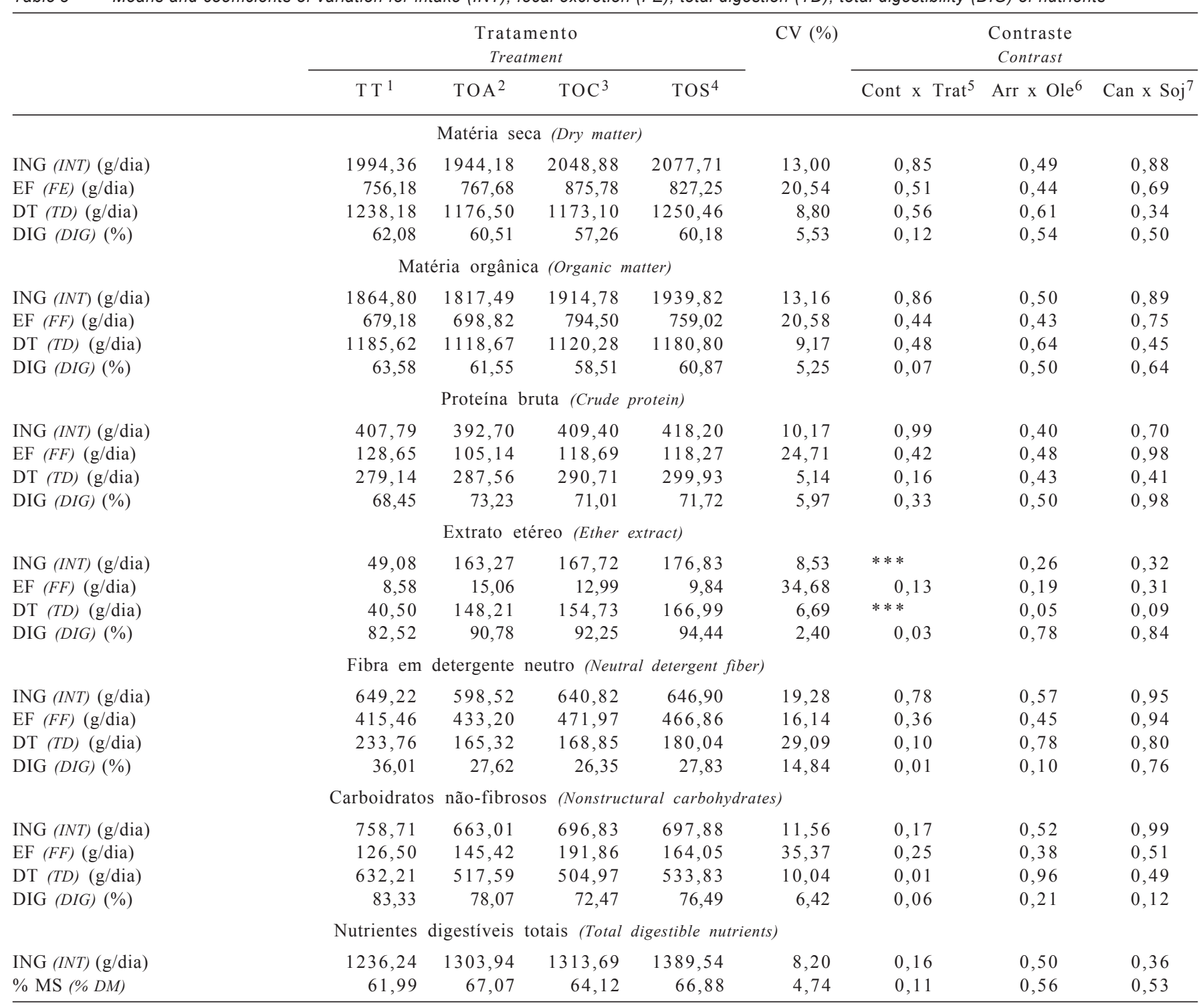

1 TT = sem adição de óleo na dieta (control diet).

2 TOA = adição de $5,1 \%$ de óleo de arroz na dieta (rice oil).

3 TOC $=$ adição de $5,1 \%$ de óleo de canola na dieta (canola oil).

4 TOS = adição de $5,1 \%$ de óleo de soja na dieta (soybean oil).

${ }^{5}$ Controle $x$ tratamentos (control $x$ oil sources).

${ }^{6}$ Óleo de arroz x óleo de sementes de oleaginosas (rice oil $x$ oily seeds).

7 Óleo de canola x óleo de soja (canola oil $x$ soybean oil).

*** Valores de $\mathrm{P}<0,001$

A absorção de ácidos graxos insaturados reduziu a ingestão de alimentos quando foram infundidos $450 \mathrm{~g} / \mathrm{dia}$ no abomaso de vacas leiteiras (Drackley et al., 1992). Segundo Loor et al. (2002), a suplementação com ácido oléico (18:1n-9) diminui a ingestão e os fluxos duodenais de MS, PB e FDA. Ressalta-se que, neste estudo, estas fontes de óleos vegetais ricos em 18:2n-6 e 18:1n-9 foram adicionadas em níveis elevados na dieta das cabras e não ocasio-naram efeito redutor sobre a ingestão de MS e outros nutrientes.
Como não houve diferença no consumo de MS entre os tratamentos, o mesmo ocorreu com a ingestão de nutrientes, à exceção do EE, pois as dietas foram formuladas para fornecer aos animais os mesmos níveis dos nutrientes avaliados (Tabela 2). Ao analisar os dados do EE, deve-se considerar que este nutriente representava $2,97 \%$ da MS no tratamento controle e 7,83\% da MS nas dietas suplementadas com óleos vegetais.

Verificou-se efeito negativo da adição de fontes de lipídios à dieta não apenas sobre o coeficiente de 
digestibilidade da parede celular (FDN), mas também sobre a digestão total dos CNF. A digestibilidade da FDN foi maior $(\mathrm{P}<0,05)$ no tratamento controle, que apresentou média de $36 \%$, enquanto naqueles com suplementação lipídica, o coeficiente de digestibilidade foi, em média, $24 \%$ inferior $(27,62 ; 26,35$ e 27,83\% para os óleos de arroz, de canola e de soja, respectivamente). A inclusão de óleos reduziu $(\mathrm{P}<0,05)$ aproximadamente $18 \%$ a digestão dos CNF da dieta de cabras Saanen. A digestibilidade da FDN e dos CNF não diferiu entre as dietas suplementadas com óleos de oleaginosas (canola e soja) e de arroz nem entre as fontes oleaginosas $(\mathrm{P}>0,05)$.

Schauff (1992), em experimento com grão de soja integral e sebo bovino (2,5 e $4 \%$ da MS), constataram que as digestibilidades da FDA, FDN e HEM não foram afetadas. Esses dados estão de acordo com os encontrados por Villaça et al. (1999), que avaliaram dietas suplementadas com 5\% de lipídios e não notaram alteração na digestibilidade da FDN quando a gordura foi introduzida na forma de óleo degomado; porém, houve decréscimo na digestibilidade com a utilização de sementes oleaginosas inteiras.

Neste estudo, as quantidades ingeridas, as digeridas e a digestibilidade total de $\mathrm{EE}$ foram maiores $(\mathrm{P}<0,05)$ para os tratamentos com fontes suplementares de lipídios na dieta. Considerando as mesmas variáveis, não houve diferenças entre óleos de oleaginosas (canola e soja) e de arroz nem entre as duas oleaginosas $(\mathrm{P}>0,05)$. Os animais alimentados com as dietas suplementadas com lipídios apresentaram médias de ingestão, de digestão total e do coeficiente de DIG do EE 244,89; 286,79 e 9,7\% superiores em relação ao tratamento controle, respectivamente.

O NDT apresentou valor médio de $65,02 \%$ da MS e não diferiu $(\mathrm{P}>0,05)$ entre as dietas. Este valor foi $11,9 \%$ inferior ao estimado utilizando-se os dados do NRC (1996), que foi de $73,84 \%$ da MS (Tabela 2).

Os dados referentes à concentração de $\mathrm{N}-\mathrm{NH}_{3}$ ruminal, $\mathrm{N}$-uréico no plasma (NUP), N-uréico no leite (NUL) e pH encontram-se na Tabela 4. A inclusão de fontes de óleos vegetais na dieta não influenciou $(\mathrm{P}>0,05)$ a concentração de $\mathrm{N}-\mathrm{NH}_{3}$ ruminal, cujo valor médio foi $23,00 \mathrm{mg} / \mathrm{dL}$. Estes dados corroboram aqueles descritos por Vargas et al. (2002), em estudo com óleo e grão de soja moído, no qual também não verificaram efeito da utilização de fontes suplementares de lipídios em nível de 7\% da MS da dieta sobre a concentração de $\mathrm{N}-\mathrm{NH}_{3}$.

Contudo, diferem dos obtidos por Villaça et al. (1999), que, utilizando dietas suplementadas com 5\% de EE na MS, por meio da inclusão de sementes de oleaginosas (soja e algodão) e de óleo de soja na dieta de bezerros holandeses fistulados, verificaram que a concentração média de $\mathrm{N}-\mathrm{NH}_{3}$ ruminal foi maior com a introdução de óleo de soja em relação às dietas controle e grão de soja, mas não em relação àquela com caroço de algodão. Nestas condições, a concentração média de $\mathrm{N}-\mathrm{NH}_{3}$ ruminal encontrada pelos autores foi $7,54 \mathrm{mg} / 100 \mathrm{~mL}$.

Igwuegbu \& Sutton (1982) e Tesfa et al. (1992) demonstraram que óleos insaturados diminuem a concentração de nitrogênio amoniacal, principalmente em razão da diminuição da população de protozoários no ambiente ruminal, entretanto, este efeito não foi avaliado neste estudo. Balieiro Neto \& Melloti (1998) avaliaram dietas com 6\% de sebo bovino e não encontraram efeito negativo sobre a ingestão de MS e a concentração de $\mathrm{N}-\mathrm{NH}_{3}$ ruminal, mesmo quando houve redução na população de protozoários.

Similarmente, Igwuegbu \& Sutton (1982), trabalhando com dieta suplementada com óleo de linhaça e Ferlay et al. (1993), com óleo de canola, verificaram redução na concentração de nitrogênio amoniacal. O mesmo efeito foi relatado por Loor et al. (2002) em resposta à suplementação lipídica a 4,8\% da MS em vacas em lactação. No entanto, a concentração média verificada pelos autores foi $9,77 \mathrm{mg} / \mathrm{dL}$, bastante inferior à média encontrada neste trabalho. Contudo, Van Nevel \& Demeyer (1988) observaram aumento da eficiência da síntese microbiana e redução da concentração de $\mathrm{NH}_{3}$ ruminal em animais consumindo óleo na dieta. Segundo os autores, provavelmente isto ocorreu em virtude do efeito sobre a defaunação e/ou a redução na população de bactérias desaminadoras.

A variação na concentração de $\mathrm{N}-\mathrm{NH}_{3}$ ruminal ao longo do dia está representada na Figura 1. Como evidenciado, as concentrações mais elevadas ocorreram aproximadamente duas horas após o fornecimento das dietas.

A amônia ruminal, originada da degradação de aminoácidos e do nitrogênio não-protéico da dieta, quando não utilizada para a síntese de proteína microbiana, é absorvida pela parede do rúmen, atinge a corrente sanguínea e passa pelo fígado, onde é metabolizada para dar origem à uréia. Uma vez na corrente sangüínea, a uréia pode difundirse livremente para o leite, justificando a alta correlação entre a concentração de nitrogênio uréico no plasma (NUP) e no leite (NUL) (Mouro et al., 2002).

A suplementação lipídica da dieta não influenciou ( $\mathrm{P}>0,05)$ o nível de NUP, que apresentou valor médio de 18,14 (mg/dL), comprovando que, nas condições em que foi realizado este experimento, a utilização das fontes adicionais de óleos na dieta não interferiu neste indicador do metabolismo do nitrogênio. Do mesmo modo, a fonte de óleo empregada na suplementação, sementes de oleaginosas (canola ou soja) ou de cereal, também não interferiu $(\mathrm{P}>0,05)$ neste parâmetro, como verificado pela análise dos contrastes avaliados. Estes dados confirmam os encontrados por 
Tabela 4 - Médias da concentração de amônia e pH ruminal e nitrogênio uréico no plasma e no leite Table 4 - Means of ruminal $\mathrm{pH}$ and ammonia $\mathrm{N}$ and concentration of plasma urea (PUN) and milk urea nitrogen (MUN)

\begin{tabular}{|c|c|c|c|c|c|c|c|c|}
\hline & \multicolumn{4}{|c|}{$\begin{array}{c}\text { Tratamento } \\
\text { Treatment }\end{array}$} & \multirow[t]{2}{*}{ CV (\%) } & \multicolumn{3}{|c|}{$\begin{array}{c}\text { Contraste } \\
\text { Contrast }\end{array}$} \\
\hline & $\mathrm{T} \mathrm{T}^{1}$ & $\mathrm{TOA}^{2}$ & $\mathrm{TOC}^{3}$ & $\mathrm{TOS}^{4}$ & & Cont $\times$ Trat $^{5}$ & Arr $x \mathrm{Ole}^{6}$ & Can $x \mathrm{Soj}^{7}$ \\
\hline NUP (PUN) $(\mathrm{mg} / \mathrm{dL})$ & 17,67 & 18,37 & 18,49 & 18,02 & 6,10 & 0,59 & 0,92 & 0,74 \\
\hline NUL $(M U N)(\mathrm{mg} / \mathrm{dL})$ & 19,34 & 17,95 & 17,72 & 17,47 & 10,48 & 0,01 & 0,15 & 0,22 \\
\hline $\mathrm{pH}$ & 6,38 & 6,44 & 6,54 & 6,53 & 0,82 & 0,01 & 0,03 & 0,72 \\
\hline
\end{tabular}

1 TT = sem adição de óleo na dieta (control diet).

2 TOA = adição de $5,1 \%$ de óleo de arroz na dieta (rice oil).

3 TOC $=$ adição de $5,1 \%$ de óleo de canola na dieta (canola oil).

4 TOS = adição de $5,1 \%$ de óleo de soja na dieta (soybean oil).

5 Controle $x$ tratamentos (control $x$ oil sources).

6 Óleo de arroz x óleo de sementes de oleaginosas (rice oil x oily seeds).

7 Óleo de canola $x$ óleo de soja (canola oil $x$ soybean oil).

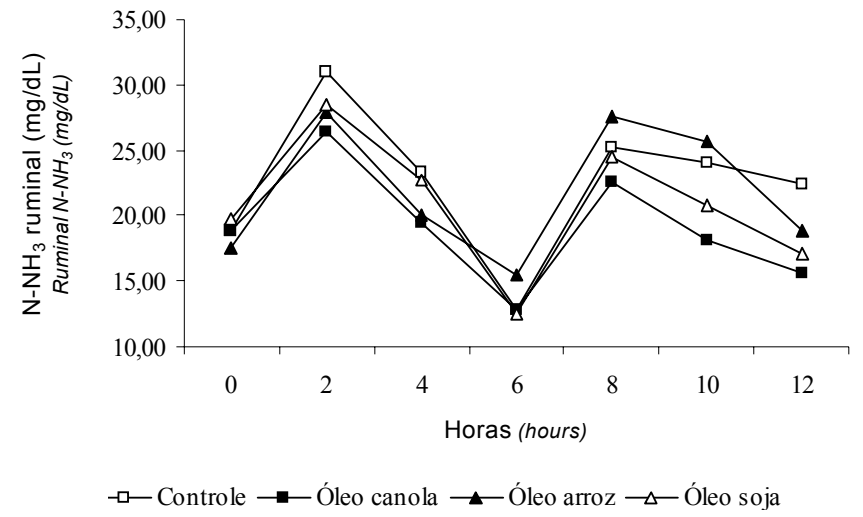

Figura 1 - Concentração de $\mathrm{N}-\mathrm{NH}_{3}$ no fluido ruminal para dietas com diferentes fontes de óleo, de acordo com o tempo após o fornecimento da alimentação.

Figure 1 - Post-feeding concentration of ruminal ammonia $N$ on goats fed diets with different sources of oil.

Schimidely et al. (1996) e Mouro et al. (2002), que obtiveram para a concentração de uréia no plasma, 36 e $38,30 \mathrm{mg} / \mathrm{dL}$, que correspondem, respectivamente, a 16,78 e $17,85 \mathrm{mg}$ $\mathrm{N}$-uréico/dL. Além disso, foram próximos aos verificados por Loor et al. (2002), que encontraram valor de 13,98 mg de $\mathrm{N}$ uréico/dL.

A concentração de uréia no leite foi superior $(\mathrm{P}<0,05)$ para o tratamento controle e, a exemplo do que ocorreu com a concentração de uréia plasmática, a análise dos contrastes não mostrou diferença $(\mathrm{P}>0,05)$ entre as fontes de óleo utilizadas na suplementação. A concentração média deste elemento entre as dietas estudadas foi de $38,88 \mathrm{mg} / \mathrm{dL}$, muito próxima à descrita por Mouro et al. (2002), de 36,87 mg/dL. No entanto, Loor et al. (2002), trabalhando com lipídios adicionados em nível de $5 \%$ da MS da dieta de vacas em lactação, encontraram média de $12,43 \mathrm{mg}$ de $\mathrm{N}$-uréico/dL, que corresponde a aproximadamente $27,62 \mathrm{mg}$ de uréia/dL para este parâmetro. Isso comprova que os dados obtidos neste estudo estão dentro da faixa de variação proposta na literatura.

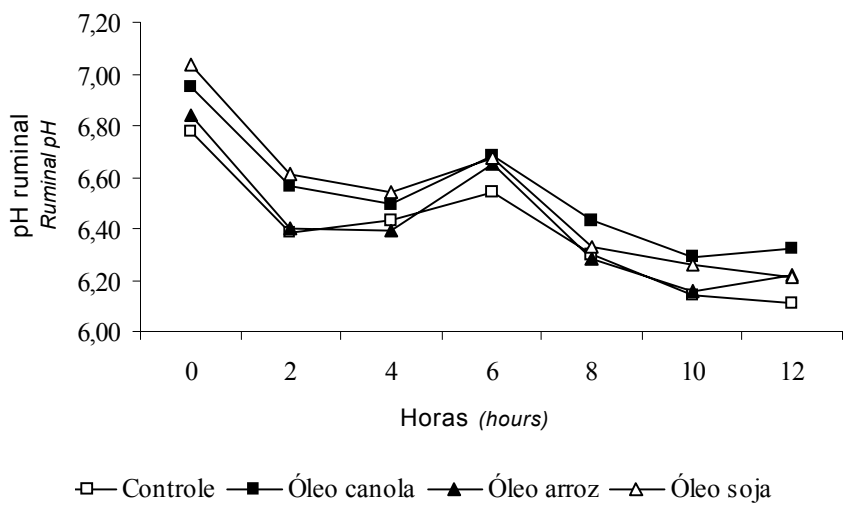

Figura 2 - pH ruminal para diferentes fontes de óleo em função do tempo após o fornecimento da alimentação.

Figure 2 - Post-feeding concentration of ruminal ammonia Non goats fed diets with different sources of oil.

A inclusão de óleo na dieta promoveu aumento do $\mathrm{pH}$ ruminal $(\mathrm{P}<0,05)$. Além disso, o aumento provocado pelas oleaginosas para este parâmetro foi superior $(\mathrm{P}<0,05)$ ao do óleo de arroz, porém não diferiu $(\mathrm{P}>0,05)$ entre as duas fontes de oleaginosas avaliadas (Tabela 4).

O comportamento do $\mathrm{pH}$ ao longo do dia (Figura 2) foi contrário ao apresentado pela concentração de $\mathrm{N}^{-\mathrm{NH}_{3}}$, em que os menores valores foram observados 4 horas após o fornecimento das rações.

Christensen et al. (1994) não observaram efeito de dietas suplementadas com óleo de milho e sebo bovino sobre o pH ruminal. No entanto, Vargas et al. (2002) observaram aumento do $\mathrm{pH}$ para as dietas suplementadas com grão e óleo de soja e atribuíram este efeito à queda do consumo de MS e à menor fermentação ruminal, que proporciona menor acúmulo de ácidos graxos voláteis, principal fator de redução do $\mathrm{pH}$. Contudo, esses autores não verificaram redução no consumo de MS, o que indica que a redução na degradação da fibra dietética reduziu a 
produção de ácidos graxos voláteis e, conseqüentemente, impediu a queda do $\mathrm{pH}$ ruminal.

\section{Conclusões}

A inclusão de óleos vegetais no nível de 5,1\% para atingir níveis de EE superiores a 7\% na MS da dieta não alterou a digestibilidade dos nutrientes e os parâmetros de fermentação ruminal de cabras em lactação.

\section{Literatura Citada}

AGRICULTURAL AND FOOD RESEARCH COUNCIL - AFRC. Energy and protein requirements of ruminants. Wallington: CAB International, 1993. 159p.

BALIEIRO NETO, G.; MELLOTI, L. Efeitos de diferentes níveis de sebo sobre a fermentação ruminal, contagem de protozoários, proporção de ácidos graxos voláteis e degradabilidade in situ do farelo de soja e do feno de tifton (Cynodon dactylon). In: CONGRESSO NORDESTINO DE PRODUÇÃO ANIMAL, 1., 1998, Fortaleza. Anais... Fortaleza: Ministério da Agricultura, 1998. p.9.

BENSON, J.A.; REYNOLDS, C.K.; HUMPHRIES, D.J. et al. Effects of abomasal infusion of long chain fatty acids on intake, feeding behaviour and milk production in dairy cows. Journal of Dairy Science, v.84, p.1182-1191, 2001.

CHALUPA, W.; RICKABAUGH, B.; HRONFELS, D.S. et al. Rumen fermentation in vitro as influenced by long chain fatty acids. Journal of Dairy Science, v.67, p.1439-1444, 1984.

CHRISTENSEN, R.A.; CAMERON, M.R.; CLARK, J.H. et al. Effects of amount of protein and ruminally protected amino acids in the diet of dairy cows fed supplemental fat. Journal of Dairy Science, v.77, p.1618-1629, 1994.

COCHRAN, R.C.; ADAMS, D.C.; WALLACE, J.D. et al. Predicting digestibility diets with internal markers: evaluation of four potential markes. Journal of Animal Science, v.63, p.1476-1483, 1986.

DRACKLEY, J.K.; KLUSMEYER, T.H.; TRUSK, A.M. et al. Infusion of long-chain fatty acids varying in saturation and chain length into the abomasum of lactating dairy cows. Journal Dairy Science, v.75, p.1517-1526, 1992.

ERLAY, A.; CHABROT, J.; ELMEDDAH, Y. et al. Ruminal lipid balance and intestinal digestion by dairy cows fed calcium salts of rapeseed oil fatty acids or rapeseed oil. Journal of Animal Science, v.71, p.2237-2245, 1993.

GOODRICH, R.D.; GARRET, J.E.; GUEST, D.R. et al. Influence of monensin on the performance of cattle. Journal of Animal Science, v.58, p.1484-1498, 1984.

IGWUEGBU, O.A.; SUTTON, J.D. The effect of varying the amount of linseed oil supplementation on rumen metabolism in sheep. British Journal of Nutrition, v.48, p.365-375, 1982.

JENKINS, T.C.; BATEMAN, H.G.; BLOCK, S.M. Butylsoyamide increases unsaturation of fatty acids in plasma and milk of lactating dairy cows. Journal of Dairy Science, v.79, p.585-590, 1996.

JENKINS, T.C.; THIES, E. Plasma fatty acids in sheep fed hydroxyethylsoyamide: a fatty acylamide that resist biohydrogenation. Lipids, v.32, p.173-178, 1997.

KELLY, M.L.; BERRY, J.R.; DWYER, D.A. et al. Dietary fatty acid sources affect conjugated linoleic acid concentrations in milk from lactating dairy cows. Journal of Nutrition, v.128, p.881-885, 1998.

LOOR, J.J.; HERBEIN, J.H.; JENKINS, T.C. Nutrient digestion, biohydrogenation, and fatty acid profiles in blood plasma and milk fat from lactating Holstein cows fed canola oil or canolamide. Animal Feed Science and Technology, v.97, p.65-82, 2002.

MARSH, W.H.; BENJAMIN, F.; MILLER, H. Automated and manual direct methods for determination of $\alpha$-linked glucose polymers in biological materials. Journal of Science Food Agriculture, v.19, n.578, 1965 .

MOURO, G.F.; BRANCO, A.F.; MACEDO, F.A.F. Substituição do milho pela farinha de mandioca de varredura em dietas de cabras em lactação: fermentação ruminal e concentrações de uréia plasmática e no leite. Revista Brasileira de Zootecnia, v.31, p.1840-1848, 2002.

NATIONAL RESEARCH COUNCIL - NRC. Nutrient requirements of beef cattle. 7.ed. Washington, D.C.: National Academy Press, 1996. 242p.

NATIONAL RESEARCH COUNCIL - NRC. Nutrient requirements of dairy cattle. 7.ed. Washington, D.C.: National Academy Press, 2001. 381p.

ROMO, G.A.; ERDMAN, R.A.; TETER, B.B. et al. Milk composition and apparent digestibilities of dietary fatty acids in lactating dairy cows abomasally infused with cis or trans fatty acids. Journal of Dairy Science, v.83, p.2609-2619, 2000.

STATISTICAL ANALYSIS SYSTEM - SAS. SAS user's guide: estatistics. Eletronic version 8.1. Cary: 2001 (CD-ROM).

SCHAUFF, D.J. Effects of feeding lactating dairy cows diets containing soybeans and tallow. Journal of Dairy Science, v.75, p.1923-1935, 1992.

SCHIMIDELY, P.; ARCHIMEDĖ, H.; BAS, P. et al. Effect of the synchronization of the rate of carbohydrates and nitrogen release of the concentrate on rumen fermentation, plasma metabolites and insulin, in the dry pregnant goat. Animal Feed Science and Technology, v.63, p.163-178, 1996.

SILVA, D.J. Análises de alimentos (métodos químicos e biológicos). 2.ed. Viçosa, MG: Universidade Federal de Viçosa, 1990. 166p.

TALKE, H.; SCHUBERT, G.E. Enzymatische harnstoffbestimmung in blut und serum im optischen test nach warburg. Klinical Wochenschr, v.43, p.174-175, 1965.

TESFA, A.T.; TOURI, M.R.; SYRJALA-QUIST, L. The effects of increasing levels of rapeseed oil in the diets of lactating milking cows on milk yield, milk compositon, blood an rumen metabolites. World Review Animal Prodution, v.27, p.34-40, 1992.

Van NEVEL, C.J.; DEMEYER, D.I. Manipulation of ruminal fermentation. In: HOBSON, P.N. (Ed.) The rumen microbial ecosystem. Essex: Elsevier Science Publishers, 1988. p.387-443.

Van SOEST, P.J.; ROBERTSON, J.B.; LEWIS, B.A. Methods for dietary fiber, neutral detergent fiber, and non-starch polysaccharides in relation to animal nutrition. Journal of Dairy Science, v.74, p.3583-3597, 1991.

VARGAS, L.H.; LANA, R.P.; JHAM, G.N. et al. Adição de lipídios na ração de vacas leiteiras: parâmetros fermentativos ruminais, produção e composição do leite. Revista Brasileira de Zootecnia, v.31, p.522-529, 2002.

VIEIRA, P.F. Efeito do formaldeído na proteção de proteínas e lipídios em rações para ruminantes. Viçosa, $\mathrm{MG}$ : Universidade Federal de Viçosa, 1980. 98p. Tese (Doutorado em Zootecnia) - Universidade Federal de Viçosa, 1980.

VILLAÇA, M.; EZEQUIEL, J.M.B.; KRONKA, S.N. Efeito de sementes de oleaginosas inteiras e óleo de soja sobre a digestibilidade in vitro e os padrões ruminais de bezerros Holandeses. Revista Brasileira de Zootecnia, v.28, n.3, p.654-659, 1999.

SNIFFEN, C.J.; O'CONNOR, J.D.; Van SOEST, P.J et al. A net carbohydrate and protein system for evaluating cattle diets. II Carbohydrate and protein availability. Journal of Animal Science, v.70, p.3562-3577, 1992.

Recebido: 30/11/04 Aprovado: 30/01/06 